\title{
Renal Autotransplantation for the Treatment of Complete Ureteral Loss: A Case Report
}

\author{
Ngoc Hung Pham' \\ William R Visser ${ }^{2}$ \\ Quoc Viet Phan-Huu (D) \\ Lance J Hampton ${ }^{2}$ \\ 'Urology Department, Hue Central \\ Hospital, Hue City, Vietnam; ${ }^{2}$ Division of \\ Urology, VCU Health System, Richmond, \\ VA, USA
}

\begin{abstract}
We present an exceptional case of a patient with complete ureteral loss. The injury of the patient's right ureter resulted as a complication of prior ureteroscopic and laparoscopic. For the treatment of complete ureteral loss, the right kidney was removed and placed into the left iliac fossa. Revascularization of the kidney was performed by anastomosis of the renal vasculatures to the external iliac vasculature. Ureteral reconstruction was performed through a Boari bladder flap. At the six-month follow-up visit, the resistive indices of the transplanted kidney proved to be in the normal range.
\end{abstract}

Keywords: renal autotransplantation, injury ureter

\section{Introduction}

A ureteral stricture is characterized by a narrowing of the ureteral lumen, causing a functional obstruction. Ureteral strictures are typically the result of ischemia, which in turn leads to fibrosis or atrophy. ${ }^{1}$ Wolf and colleagues define stricture as ischemic when the result of surgical interventions or radiation therapy and nonischemic if it is caused by spontaneous stone passage or a congenital abnormality. Additionally, poorly placed sutures or surgical clips during any intra-abdominal or retroperitoneal operation can cause mechanical obstruction. ${ }^{2}$

A retrospective review identified 55 patients with iatrogenic ureteral injuries during 16 years and noted the majority of ureteral injuries occurred during gynecologic procedures $(55 \%)$. The remainder of the injuries occurred during urologic $(25 \%)$, colorectal $(15 \%)$, and vascular $(5 \%)$ procedures. $^{3}$

Renal autotransplantation is usually considered a last resort in the spectrum of surgical treatment for extensive ureteral tissue loss. ${ }^{4}$ It was first reported by Hardy in 1963 when he repaired a proximal ureteral injury by reimplanting the repaired organ into the ipsilateral iliac fossa. ${ }^{5}$ Managing renal disease via a "benchwork" approach soon became a novel idea pursued worldwide. ${ }^{6}$ It is valuable for any disease where intervention on the kidney would expose it to prolonged warm ischemia resulting in permanent renal damage, such as complex distal renal arterial disease $^{7}$ and large kidney tumors where renal preservation is imperative. ${ }^{8,9}$

An alternative to renal autotransplantation in patients with extensive ureteral tissue loss is ileal ureteral substitution; however, ileal substitutions may not be possible in patients with prior bowel resections. Additionally, the long-term consequences of intestinal interposition within the urinary tract are not completely known and must be considered when utilized. ${ }^{10}$ When an ileal substitution is an unfavorable option, autotransplantation may be the only choice.
Correspondence: Ngoc Hung Pham Urology Department, Hue City Hospital, 16 Le Loi Street, Hue City, 530000, Vietnam

Tel +84903591678

Email drhungg@gmail.com 
In Vietnam, renal autotransplantation has been performed to negate the effects of prolonged warm ischemia time for diseases, such as large kidney tumors, large kidney stones, severe kidney injuries, or complex distal renal arterial diseases. In the present case, we report the first successful renal autotransplantation in a patient suffering from extensive ureteral loss after a laparoscopic stone surgery.

\section{Case Presentation}

A 50-year-old woman with a past medical history of kidney stones underwent uretroscopy for removal of a proximal right ureteral stone. During the operation, she had a ureteral avulsion and subsequently underwent a laparoscopic right ureteral re-implant with the removal of the kidney stone. She presented three months postoperatively with right flank pain and fever and was found to have hydronephrosis and a perinephric fluid collection of the right kidney on ultrasonography. A percutaneous nephrostomy tube was placed after the patient underwent failed attempts at retrograde ureteral stent placement and open ureteral stent placement.

An antegrade nephrostogram (Figure 1), computed tomography (CT) abdomen and pelvis with intravenous contrast

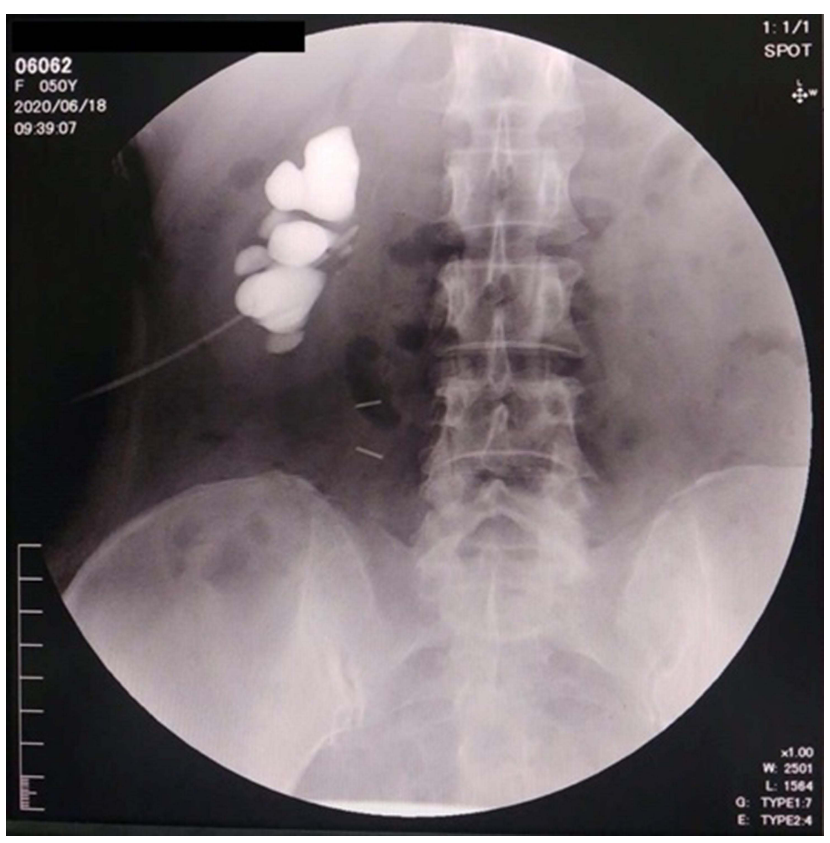

Figure I Antegrade nephrostogram demonstrating hydronephrosis with retained contrast in the collecting system of the right kidney. There is no contrast visualized within the right ureter. Two clips can be identified along the anatomical path of the right ureter.

(Figure 2), and cystoscopy were performed revealing an extensive ureteral loss of the right side. Initial imaging suggested preserved function of the kidney function; therefore,

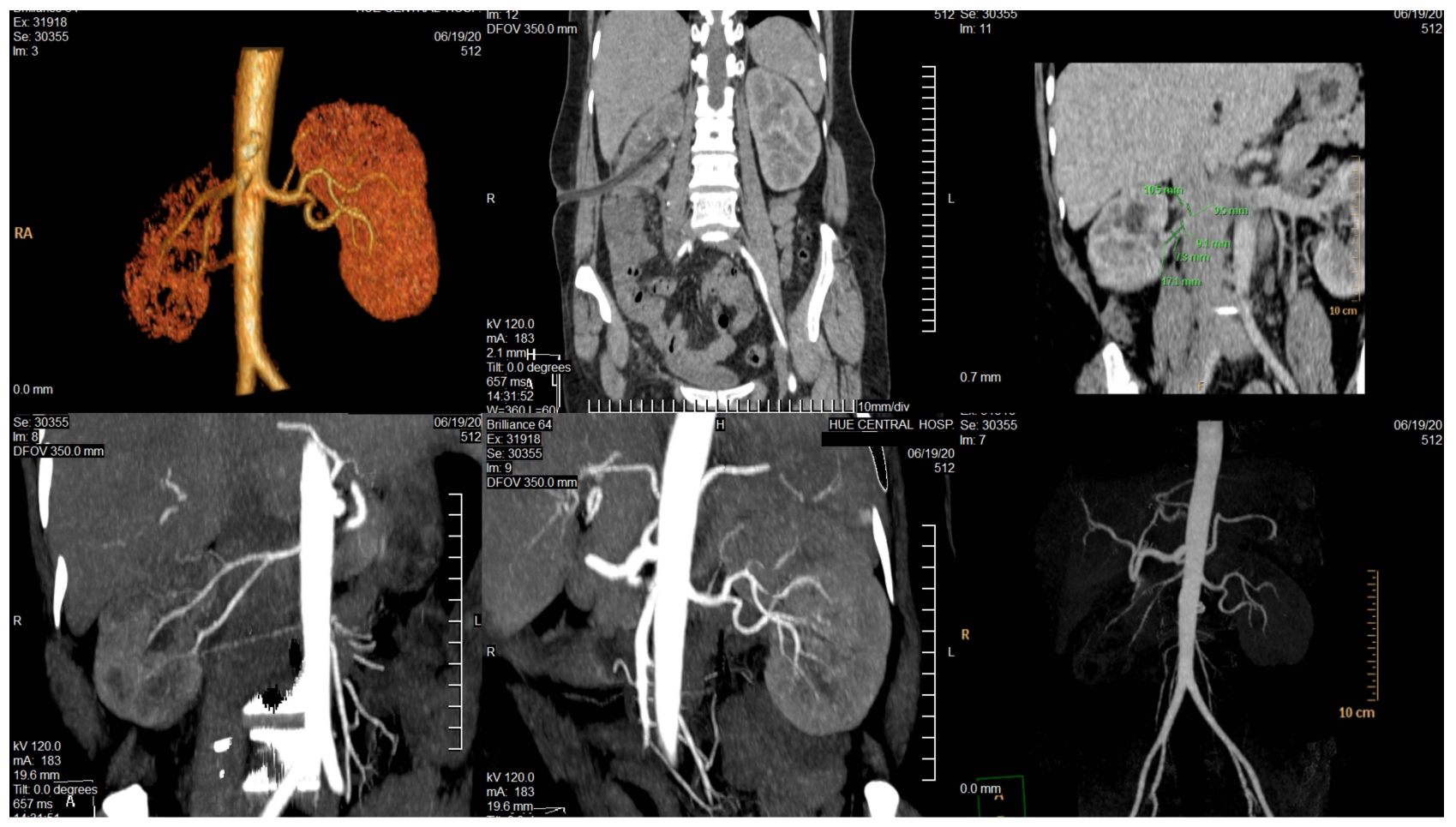

Figure 2 Abdomen and pelvis CT scan with intravenous contrast in the arterial demonstrates two main renal arteries. There is contralateral renal hypertrophy with preserved renal parenchyma on the ipsilateral side. 
the surgeon was elected to perform a renal autotransplantation. A retroperitoneal nephrectomy was performed through a flank incision. The right kidney was then placed into the left iliac fossa through a Gibson incision (Figure 3). The kidney was revascularized by performing an anastomosis of the two renal veins to the left external iliac vein and the two renal arteries to the left external iliac artery. A neoureter was constructed using the Boari technique due to an absent ureter and renal pelvis. Prior to closure, a double J ureteral stent and two surgical drains were left in place. Surgical drains were removed on postoperative day five and the patient was discharged after all necessary criteria were met.
The ureteral stent was removed cystoscopically at the one-month post-operative mark. The patient then returned to the clinic two months post-operatively for follow-up. Her incisions were well healed, and she had appropriate urine output. The transplanted kidney showed normal arterial and venous flow on Color Doppler ultrasonography. The mean parenchymal arterial vascular resistance of the transplanted kidney was 0.86 . The height, anteroposterior diameter, and transverse diameter of the transplanted kidney were $80 \mathrm{~mm}, 39 \mathrm{~mm}$, and $42 \mathrm{~mm}$, respectively.

The abdomen and pelvis CT scan 2 months (Figure 4) and 6 months (Figure 5) after the surgery showed that
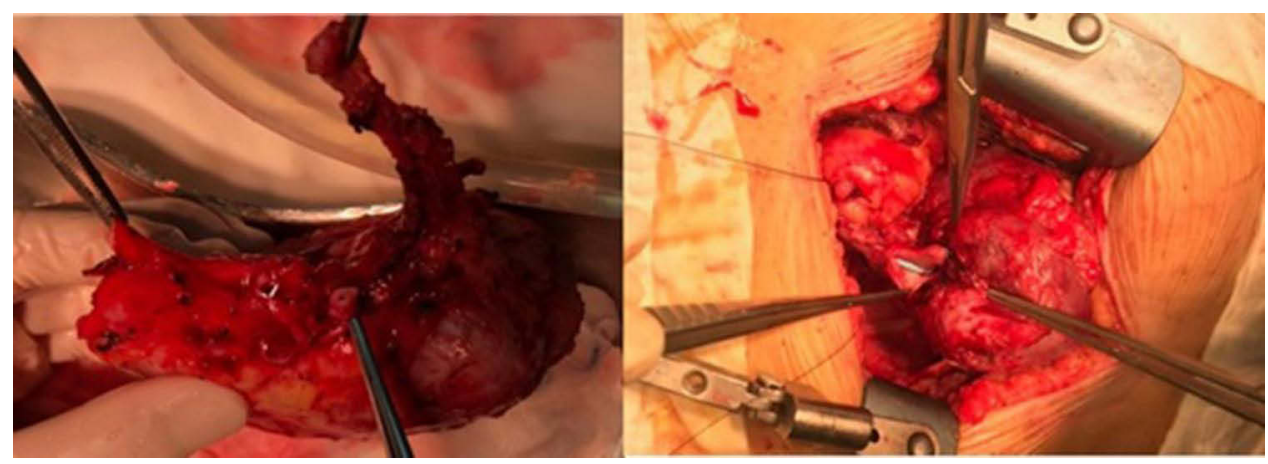

Figure 3 The image on the left depicts the right kidney after retroperitoneal nephrectomy. The diseased ureter can be seen at the top of the image. The right image shows the surgeons placing the right kidney into the left iliac fossa via a Gibson incision.
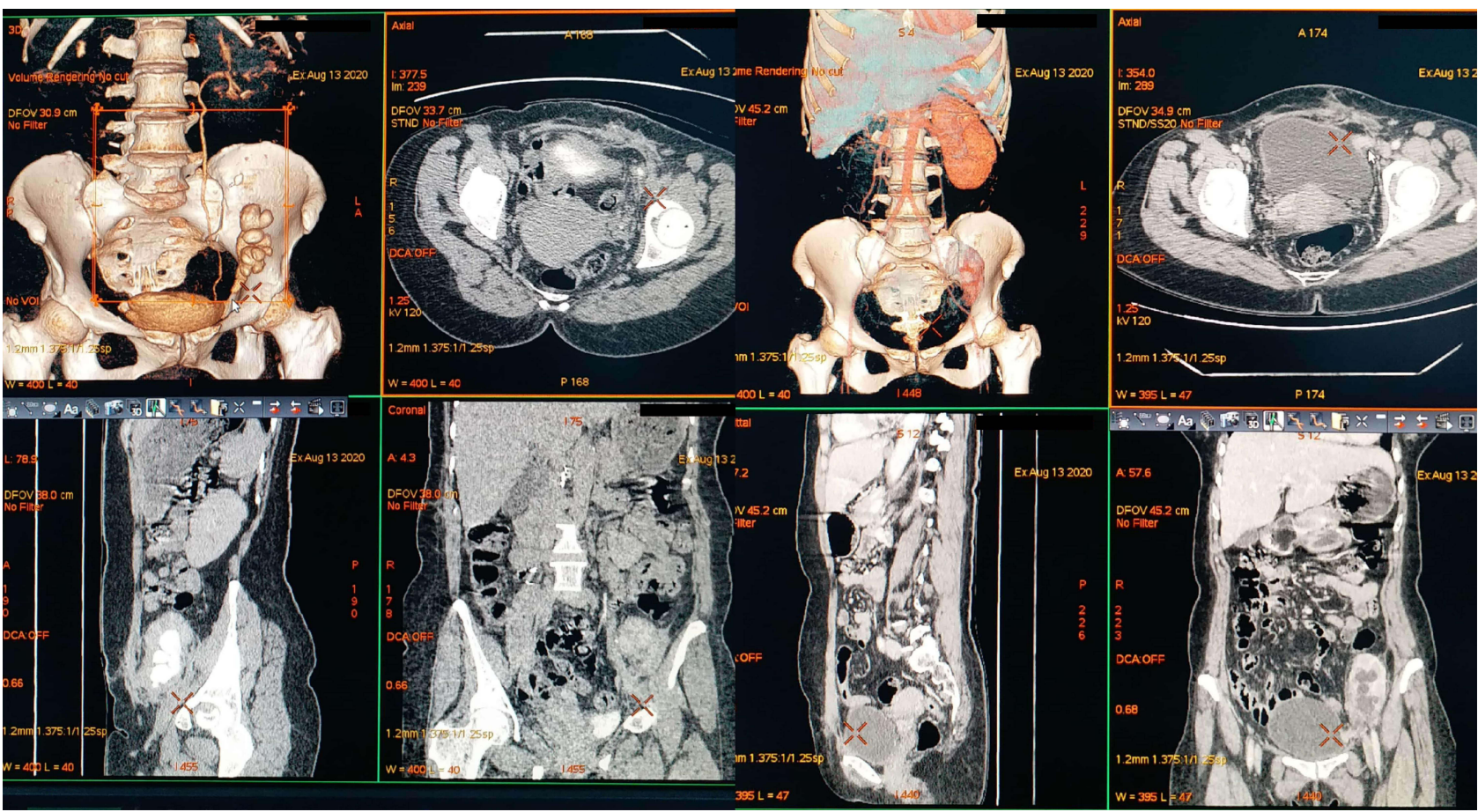

Figure 4 Abdomen and pelvis CT scan 2 months after surgery shows significant hydronephrosis of the transplanted kidney. However, this is the old hydronephrosis (the antegrade nephrostogram before the surgery have shown that). 


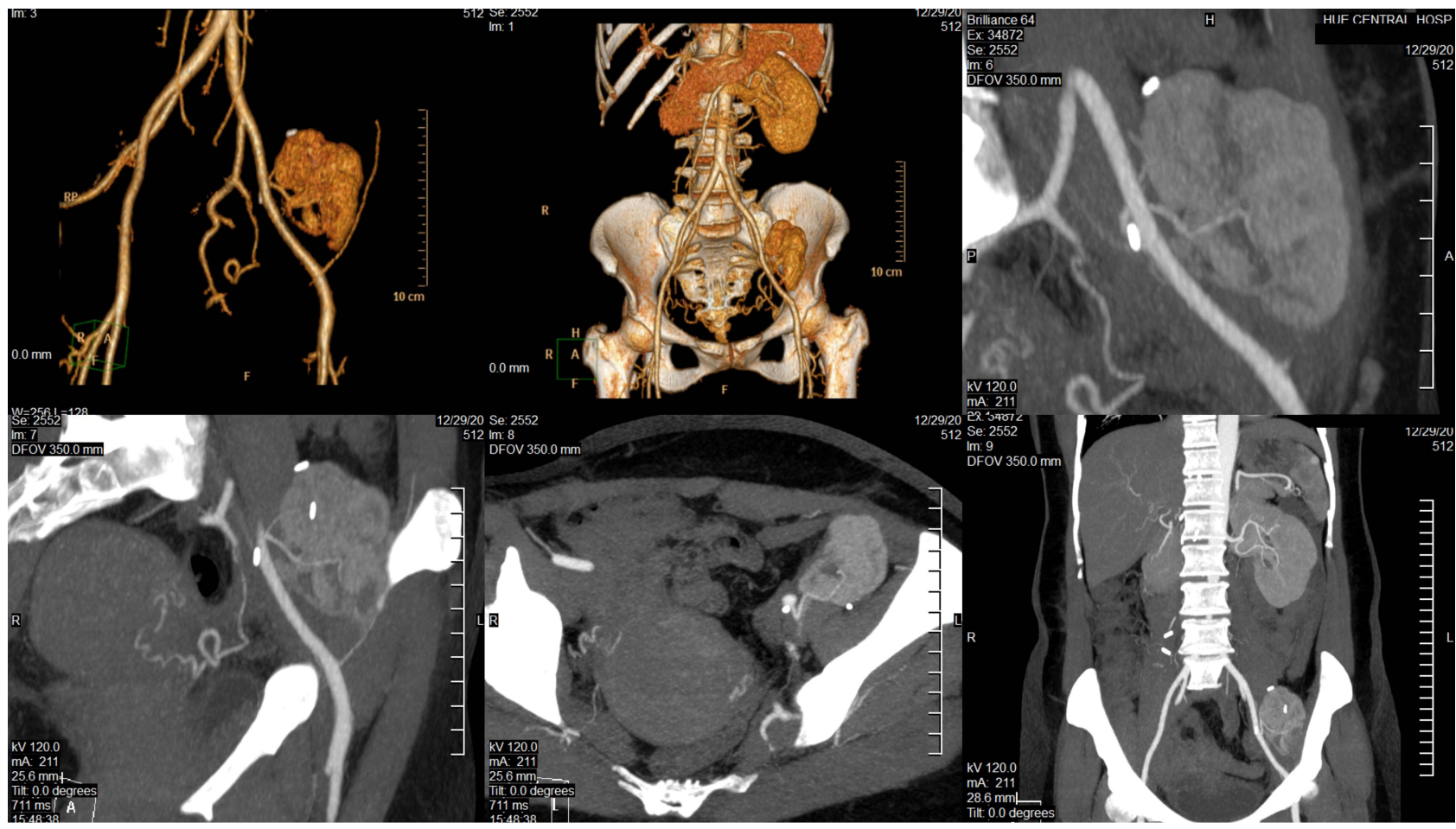

Figure 5 Abdomen and pelvis CT scan 6 months after surgery (the kidney seem to be smaller because the slices are not via the main axis of the kidney).

although the transplanted kidney was smaller than that before the surgery, its morphology and function were still in an acceptable general range.

\section{Discussion}

The extensive ureteral tissue loss in this case was a complication of previous urologic procedures. When the patient presented with acute right flank pain and fever, her workup demonstrated preserved renal function. This is further temporized by the placement of a percutaneous nephrostomy tube. While this proximal diversion may help preserve the long-term function of the kidney, it is not a good long-term management option due to the increased risk of infections and poor quality of life.

It is evident that appropriate decision-making and timely surgical intervention can prevent the need for nephrectomy and possible complications in the future. In general, management of ureteral avulsion depends on the location of the injury, the length of the traumatized ureter, time of diagnosis, patient's age, and general health. There are different therapeutic methods for the treatment of this condition. A Boari flap and psoas hitch technique may be used to bring span to the missing portion of the ureter. The Boari bladder flap procedure can be a safe and relevant choice in the management of challenging complications after heterotrophic (either allogeneic or autotransplant) renal transplant, allowing minimally invasive urologic surgery, no need for use of bowel segments, and no potential risk for the contralateral kidney. ${ }^{11}$ Potential benefits of autotransplant included providing adequate surgical exposure, a bloodless surgical field, and hypothermic protection of the kidney against ischemia. ${ }^{12}$ An ileal interposition and/or uretero-ureterostomy can also be used to complement or supplement a Boari flap or psoas hitch. It is important to remember that ileal interposition surgery involves complications such as electrolyte disturbances and stone formation. ${ }^{13}$ Moreover, it is difficult to perform ureteroplasty with long-severe ureteral injury and an abdominal incision previously. When ureteral reconstruction cannot be performed in an orthotopic position, renal autotransplantation may be the best option. ${ }^{14}$

It is evident that such surgical procedures require substantial expertise among the involved healthcare team. Patient selection is critical and should be based on health status, age, preservation of renal function, and inability to perform reconstruction in the orthotopic position. Autotransplantation was performed in this situation after the patient was fully evaluated, and the surgical team concluded that less aggressive interventions would have a low probability of success. 
The limitations of the study are that we did not have a renal nuclear scan test to evaluate the renal function before and after the surgery. In fact, our center can perform a renal nuclear scan test but at that time the renal nuclear scan system did not work. However, computed tomography (CT) of abdomen and pelvis with intravenous contrast showed that the size and the thickness of the right renal parenchyma were still in the normal range. In addition, the right renal cortex had a good enhancement in arterial phases, and the contrast was excreted into the collecting system in the excretory phase well.

\section{Conclusion}

This case represents the first reported renal autotransplantation performed in Vietnam due to an extensive ureteral stricture. The right kidney was transplanted to the left iliac fossa, and a Boari flap was used to reconstruct the diseased ureter. Urologic surgeons in Vietnam may consider this a viable surgical alternative when other interventions are deemed to be inappropriate.

\section{Ethics Approval and Consent to Participate}

The case reports received approval for publication from the Ethics Committee of Hue Central Hospital.

\section{Consent for Publication}

Written informed consent for publication of the clinical details and clinical images was obtained from the patient.

\section{Disclosure}

Authors declare no conflicts of interest.

\section{References}

1. Kapogiannis F, Spartalis E, Fasoulakis K, Tsourouflis G, Dimitroulis D, Nikiteas NI. Laparoscopic and robotic management of ureteral stricture in adults. In Vivo. 2020;34(3):965-972. doi:10.21873/invivo.11864

2. Wolf JS Jr, Elashry OM, Clayman RV. Long-term results of endoureterotomy for benign ureteral and ureteroenteric strictures. $J$ Urol. 1997;158(3 Pt 1):759-764. doi:10.1016/S0022-5347(01)64308-8

3. Elliott SP, McAninch JW. Ureteral injuries: external and iatrogenic. Urol Clin North Am. 2006;33(1):55-66, vi. doi:10.1016/j. ucl.2005.11.005

4. Bodie B, Novick AC, Rose M, Straffon RA. Long-term results with renal autotransplantation for ureteral replacement. $J$ Urol. 1986;136 (6):1187-1189. doi:10.1016/S0022-5347(17)45278-5

5. Hardy JD. High ureteral injuries. Management by autotransplantation of the kidney. JAMA. 1963;184:97-101. doi:10.1001/ jama.1963.03700150051008

6. Dean RH, Meacham PW, Weaver FA. Ex vivo renal artery reconstructions: indications and techniques. J Vasc Surg. 1986;4 (6):546-552. doi:10.1016/0741-5214(86)90167-9

7. Novick AC, Straffon RA, Stewart BH. Experience with extracorporeal renal operations and autotransplantation in the management of complicated urologic disorders. Surg Gynecol Obstet. 1981;153(1):10-18.

8. Boeminghaus F, von Spiess H. [Experience with tumors in solitary kidneys without hypothermia nor extracorporal surgery (author's transl)]. Urologe A. 1981;20(4):190-195. German.

9. van der Velden JJ, van Bockel JH, Zwartendijk J, van Krieken JH, Terpstra JL. Long-term results of surgical treatment of renal carcinoma in solitary kidneys by extracorporeal resection and autotransplantation. $B r J$ Urol. 1992;69(5):486-490. doi:10.1111/ j.1464-410X.1992.tb15593.x

10. Kocot A, Kalogirou C, Vergho D, Riedmiller H. Long-term results of ileal ureteric replacement: a 25 -year single-centre experience. $B J U$ Int. 2017;120(2):273-279. doi:10.1111/bju.13825

11. Tonyali S, Haberal HB, Bilen CY, Aki FT. Feasibility of Boari Bladder Flap Procedure in Patients With Heterotrophic Renal Transplant. Exp Clin Transplant. 2019;17(5):599-603. doi:10.6002/ ect.2018.0395

12. Azhar B, Patel S, Chadha P, Hakim N. Indications for renal autotransplant: an overview. Exp Clin Transplant. 2015;13(2):109-114.

13. Milonas D, Stirbys S, Jievaltas M. Successful treatment of upper ureteral injury using renal autotransplantation. Medicina. 2009;45 (12):988-991. doi:10.3390/medicina45120126

14. Alapont JM, Broseta E, Oliver F, Pontones JL, Boronat F, JimenezCruz JF. Ureteral avulsion as a complication of ureteroscopy. Int Braz $J$ Urol. 2003;29(1):18-22; discussion 3. doi:10.1590/S167755382003000100004

\section{Publish your work in this journal}

Research and Reports in Urology is an international, peer-reviewed, open access journal publishing original research, reports, editorials, reviews and commentaries on all aspects of adult and pediatric urology in the clinic and laboratory including the following topics: Pathology, pathophysiology of urological disease; Investigation and treatment of urological disease; Pharmacology of drugs used for the treatment of urological disease. The manuscript management system is completely online and includes a very quick and fair peer-review system, which is all easy to use. Visit http://www.dovepress.com/ testimonials.php to read real quotes from published authors. 